Journal of the Scholarship of Teaching and Learning, Vol. 21, No. 2, June 2021, pp. 140-143. doi: 10.14434/josotl.v21i2.28684

\title{
Using Book Clubs to Support Inquiry in Teacher Education
}

\author{
Patrick Dean Hales \\ South Dakota State University \\ Laura Hasselquist \\ South Dakota State University \\ Tony Durr \\ South Dakota State University
}

\begin{abstract}
The bombardment of information on students in higher education has created a need for not only information processing skills but improved communicative competence and interpersonal relationship skills. In an attempt to address this, we have implemented book clubs in our undergraduate teacher education courses. In these book clubs, we facilitate students in both critique and analysis of perspectives at difference with one another as well as the process of communicating on a professional level. The results have been students who feel more confident in evaluating literature and hosting conversations with critical elements.
\end{abstract}

Keywords: communication skills, textual analysis, communities of practice, professional collaboration, learning communities

\section{Objectives}

The constant creation and availability of information online and in the media has complicated the process of validation and analysis, especially in education contexts. In 2016, the word of the year from Oxford Dictionaries was "post-truth." "Post-truth" refers to situations or perspectives in which facts have less effect on opinion than emotions and personal beliefs (The Oxford Dictionaries, 2016). In a "post-truth" era, the opportunity to embark on journeys of thought and exercises of the mind are essential to learning and navigating the complex social and political reality we live in. With this at heart, we presented teacher education students with a choice of books of varying perspectives and backgrounds to frame their discussions of education topics. These students participated in book clubs focused on critiquing the ideas and perspectives authors presented. Our two objectives for this were (1) to move beyond lecture-style presentation as the primary teaching method in larger classes by opening dialogue through the development of interpersonal communication skills among students, and (2) to de-essentialize textbooks as fonts of knowledge through inquiry.

\section{Perspectives}

Traditional practice is to attach each university course to a textbook. At our university, this practice has gone so far as to require instructors who choose to forgo a textbook to actively opt out with the University Bookstore during each semester's course preparation. We believe that default use of catchall textbooks and reading lists can hinder student development. Presenting the limited perspectives of one or a few textbooks in a course can send the wrong message to preservice teachers; namely, that those perspectives are the "right" ones. A National Council on Teacher Quality report found that the most popularly adopted teacher education textbooks do very little to advance what we know about 
learning and cognitive psychology (Pomerance, Greenberg, and Walsh, 2016). Our use of book clubs for exploration and critique is in lieu of having a textbook for the courses in which we teach.

Books clubs can provide excellent practice at professional collaboration among preservice teachers (Burbank, Kauchak, \& Bates, 2010). Opportunities abound to develop communities of practice (Kietzmann et al., 2013; Wenger, 1998) in situations like book clubs where the goal is discussion and dissection of ideas. We believe that through inquiry-based communities of practice, students can both overcome the constraints large class sizes and surmount some obstacles of the "post-truth" era, where the loudest, simplest voice sometimes gets mistaken for fact.

\section{Modes of Inquiry}

We implemented a book club task over four semesters in three different required teacher education courses, most of which exceeded 40 students. These courses focused on educational psychology, classroom management, motivation, and inquiry-based instruction. With each iteration we adapted the assignment to the particular course's content and implemented improvements based on prior trials. We choose books on a few criteria and usually with feedback from colleagues who do not teach the course. We choose two books which are popular or well-known in education. These books might be on education department or teacher professional development common reads. The other books are less known and more technical with regard to strategies. This provides for a variety of interactions between the book club groups, with some texts more focused on theory and others on practice. Most significantly to book selection, we lay out the course objectives and determine texts which could generate conversation around those topics. The following describes how we implemented our book clubs, with a view to how this model could be utilized in a variety of classrooms.

On the first night of class, we gave students a brief overview of each book and allowed a few minutes for students and instructors to preview and discuss the books. Students were then asked to select a book. We recommend selecting only four book options; the limited number makes roundtable presentations logistically easier and supports deeper learning, particularly on the books which students did not select but will be learning about from peers. Students should be evenly divided among the book options, but they may need encouragement to move and even out groups. We recommend four students in each reading group; larger groups tend to compromise student engagement and accountability, particularly when presenting in small groups to one another..

In the weeks following book selection, students met together in their discussion groups weekly about eight times, in class typically. This was easier in three-hour, weekly courses; for shorter courses, we required students to meet between class meetings the same number of times as a discussion assignment. Because goal orientation is essential in professional learning communities (DarlingHammond, Hyler, \& Gardner, 2017), groups were given time to create group norms and expectations and to set weekly reading goals toward finishing the book in the allotted time for the semester. As the activity continued, instructors modeled and led students through several strategies designed to promote small group discussion, focusing in particular on productive critique of ideas. Post-meeting debriefs at the end of each in-class meeting facilitated the strength of group dynamics of communication. These debriefs followed a process modeled by the instructors prior to beginning the group meetings. The instructors also circulated throughout the room to provide feedback and prompt groups as needed.

After a few weeks, students each gave a presentation, called a roundtable, to a small group of their classmates. These groups are different from their discussion groups for the books and are made up of classmates from other book groups. For this phase, we recommend using a jigsaw model where each presentation group is made up of individuals representing all selected books, so all students can learn a little about each text while also having the opportunity to critique ideas. In these presentation

Journal of the Scholarship of Teaching and Learning, Vol. 21, No. 2, June 2021. josotl.indiana.edu 
groups, students each lead a discussion with their peers about the book they had been reading. Prior to leading the discussion, students should have developed discussion questions about the text.

Having a presentation early in the book club process is designed to encourage students to start dissection and analysis early rather than waiting to practice these skills on the entirety of the book at the end of the course. The timing also serves to generate conversations across groups of students engaging with the varied texts. We encourage instructors utilizing this model to help students provide feedback to one another. This is often a difficult task for students to perform deftly while they are still developing their professional identity. We provided students specific guidance on how to present feedback in a collaborative professional setting using the Critical Friends Group Protocol for warm and cool feedback (National School Reform Faculty, 2016).

The book clubs met again a few more times to finish discussing their book and to reflect on the roundtable presentations. During a second roundtable with a mixed group of students not in their book group, students made final presentations by each leading discussions which built upon the conversations and feedback of the first presentation. The second roundtable presentation allowed students the opportunity to improve their application of the discussion tools instructors presented. After each roundtable, students provided peer feedback via a cloud document based on guiding questions. Students also individually reflected and submitted thoughts and goals using the same questions. Emphasizing personal improvement helped support students' development of a growth mindset (Dweck, 2007). Grading for this assignment was handled holistically, with grade requirements and expectations being described to students ahead of time and then being marked after all portions of the assignment were completed.

\section{Evidence and Conclusions}

Most of our feedback about the assignment comes from the reflections at the end of the assignment students complete and one-on-one meetings that occur at the end of our courses between the student and the instructor. Nearly all students who participated in our book clubs have expressed their enjoyment of the model and have felt they grew professionally from reading and having the opportunity to collaborate and discuss ideas. In written reflection, most participants are able to identify a variety of ways this information can help them toward their future goals, particularly related to teaching. Several students have noted the importance of having the space to disagree and offer rational dissent. This notion stood out; in the "post-truth" era, marked by misinformation and a dearth of interpersonal communication skills, book club participants are recognizing, through their own experiences, how essential processing information can be. As one student said, "I don't get the chance to disagree very much in classes; I'm glad we got to do that here." Adding to that notion, another student said, "Sometimes I just feel like we're talking in classes. I like that we had a reason to talk."

Notable developmental characteristics emerged from examining written reflections and notes from course exit meetings. Students recognize the difference between talking at someone and teaching them. Through two rounds of presentation, students develop greater confidence as facilitators and presenters, and they begin to realize the importance of preparation and having probing questions ready. Students learn to effectively utilize appropriate methods of professional interpersonal communication, even in situations where group members disagree. Student feedback from reflections and the course exit meetings noted the value of being able to disagree and build arguments for or against others' views.

Another beneficial component to our process is the regularity and norming process of the group meetings. Meeting regularly and with agreed-to expectations helps motivate and incentivize students to keep on pace with their peers. More than half of students indicate how organizing these groups had a beneficial effect on their development as a teacher. Collaboration improves as

Journal of the Scholarship of Teaching and Learning, Vol. 21, No. 2, June 2021. josotl.indiana.edu 
relationships form among students in each group. We have observed groups regularly communicating on their devices to continue the conversations beyond the assigned class time and even beyond the semester the book clubs met.

We find it necessary to help students who are unsure of how to engage in critical discussions. We offer discussion prompts sometimes to give students a place to start when they are unsure of what to do. We found the need for a bit of de-programming regarding expectations of a book discussion. Many students initially treat the experience as a traditional book report. They provide a synopsis rather than an analysis. This can be ameliorated by the debriefs of discussion and through incorporating meeting regularity into the process. Once the process and protocol of critique and analysis begins to make sense on an individual level, group collaboration typically becomes smoother and more productive.

Our book club process reveals many positive outcomes, particularly with students' interpersonal communication skills and professional development. After this experience, a majority of students reported some positive change in their outlook or learning. As educators, we must continually find ways to respond to society and help students learn and develop in their contemporary reality. We

have found powerful and promising results in focusing on communication through use of the described book club process.

\section{References}

Burbank, M., Kauchak, D., \& Bates, A. (2010). Book clubs as professional development opportunities for preservice teacher candidates and practicing teachers: An exploratory study. The New Educator, 6, 56-73.

Dweck, C. (2007). Mindset: The new psychology of success. New York, NY: Penguin Random House.

Kietzmann, J., Plangger, K., Eaton, B., Heilgenberg, K., Pitt, L., \& Berthon, P. (2013). Mobility at work: A typology of mobile communities of practice and contextual ambidexterity. Journal of Strategic Information Systems, 3(4), 282-297.

NSRF (2015). Tuning Protocol. National School Reform Faculty.

The Oxford Dictionaries. (2016). Word of the Year is Post-Truth. https:/ / en.oxforddictionaries.com/word-of-the-year/word-of-the-year-2016.

Pomerance, L., Greenberg, J., \& Walsh, K. (2016). Learning About Learning. National Council on Teacher Quality.

Wenger, E. (1998). Communities of Practice: Learning, Meaning, and Identity. Cambridge, MA: Cambridge University Press. 